\title{
Improvement of the load capacity of the road overpass as a result of repairs after breakage caused by vehicle impacts
}

\author{
Mikołaj Miśkiewicz ${ }^{1}$, Dawid Bruski ${ }^{1, *}$, Jacek Chróścielewski ${ }^{1}$ and Krzysztof Wilde ${ }^{1}$ \\ ${ }^{1}$ Gdańsk University of Technology, Faculty of Civil and Environmental Engineering, Department of \\ Mechanics of Materials and Structures, 11/12 Gabriela Narutowicza Street, 80-233 Gdańsk, Poland
}

\begin{abstract}
Damages of spans of the overpass caused by impact of underpassing vehicles are relatively frequent. Objects that use prefabricated load-bearing elements that are not designed for such impacts are particularly exposed. After impact, such structural elements suffer extensive damage that must be repaired. Taking advantages of this recovery actions it is worth to perform strengthening that will protect object against possible future impacts. In this study the influence of the structural strengthening of the damaged overpass on its strength parameters is investigated. For this purpose the advanced computational model was created. The numerical model includes the response of the reinforcement and prestressing tendons. This model enables precise description of damage caused due to the vehicle's impact and further analysis of re-impact of the strengthened structure.
\end{abstract}

\section{Introduction}

The impacts of vehicles on bridge objects happen relatively often. Most of them are the impacts into supports [1] and spans [2], especially their lower parts. During design process, this type of accidental loads are often not taken into account. Impacts may occur during the construction of objects as well as during their use. Damage caused as a result of vehicle collisions with bridges can be significant and may cause human injuries or casualties as well as economic losses related to high costs of repairs, delay of investment process when the accident happens during the bridge construction or partial or complete exclusion of use for the repair time in the case of impact into viaducts under operation.

Nowadays, numerical simulations are commonly used to study dynamic phenomena such as, for instance, crash tests [3] or analysis of the vehicle's impact into bridge [4]. With use of simulations based on Finite Element Method, one can analyse damage of bridges [5, 6], impacts into objects as well as impacts into various types of safety devices installed on the bridge like safety barriers [7]. It is purposeful to apply explicit integration schemes to the calculations of complex dynamic problems since these procedures significantly accelerate the calculations. A recognized tool for fast-changing processes analysis is the LS-DYNA system.

\footnotetext{
*Corresponding author: dawid.bruski@pg.edu.pl
} 
The article focuses on the analysis of the properties of the overpass during its construction, which was strengthened after two impacts by vehicles. The numerical model of the impact event has been developed. This model includes advanced material definitions and uses nonstandard procedures for tendons pre-stressing. The method of bridge strengthening was proposed in the form of additional auxiliary reinforced beam localized between two end girders. The strengthening had been designed not only to repair damage caused by the impact, but also to protect the object against future accidents. On the basis of the model of the strengthen overpass the numerical simulation were conducted in order to assess how the repairs affect the safety and strength of the structure.

\section{Description of the road overpass and accidents}

The considered WD-113 overpass (Fig. 1) is located along the S-6 expressway at

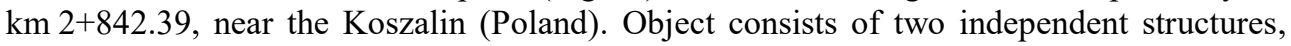
namely: WD-113L and WD-113P. They have been designed as a two-span concrete objects. The load-bearing elements are T-type prefabricated prestressed concrete beams (length $24.0 \mathrm{~m}$, height $1.0 \mathrm{~m}$ ) and a reinforced concrete slab over the T-beams (height $0.24 \mathrm{~m}$ ). The crossgirders are located over the abutments and over the intermediate supports. The total length of the WD-113P object is equal to $48.90 \mathrm{~m}$ and the total width is $18.95 \mathrm{~m}$.

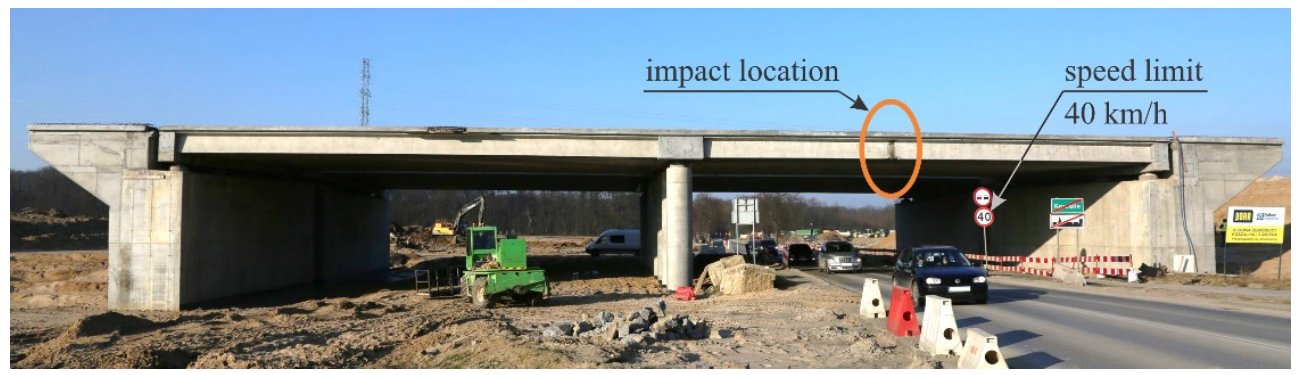

Fig. 1. Overall view of the bridge. The location of the impact is marked orange.

The damage of the overpass were caused by two impacts of the vehicle. The first impact (10.11.2017) caused by hydraulic lift crane mounted on the truck resulted in significant damage of the structure including:

- losses of concrete in the impact location,

- significant horizontal cracks under the beam flange on both sides,

- diagonal cracks on vertical and bottom surfaces on both sides of the impact place,

- hairline crack on the upper surface of the slab, between two end girders.

During the inspection, the failure of the prestressing tendons was not confirmed. As a result of the second accident $(01.12 .2017)$ the bottoms of the girders were scratched which did not endanger the safety of the structure. Therefore, it was decided to only analyse the first collision event. The impact point is shown in Fig. 1 and the summary of the damage is given in Fig. 2. 


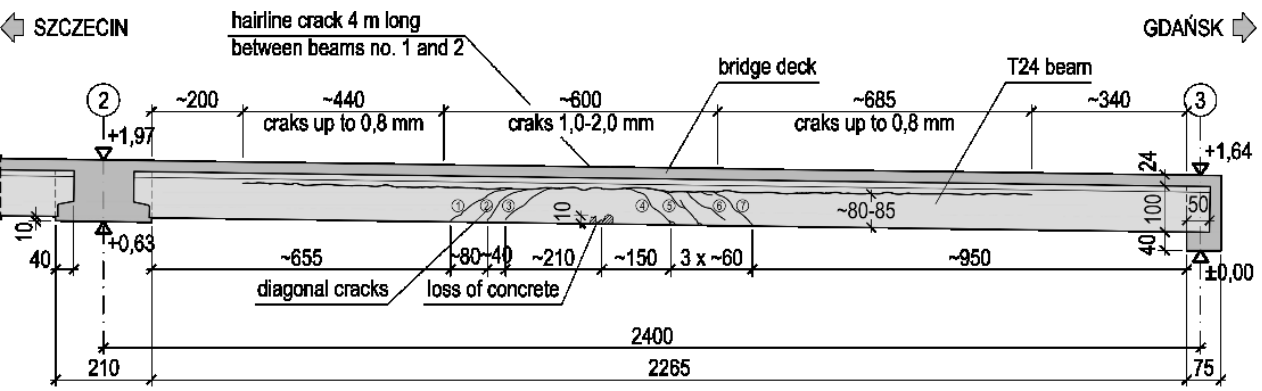

width of diagonal cracks:

$0,1 \mathrm{~mm}$ (6) $0,2 \mathrm{~mm}$ (1) (2) (3) (5) $0,3 \mathrm{~mm}$ (4) (7) note: dimensions in [cm]

Fig. 2. The drawing of damage of the structure.

\section{Reconstruction of impact conditions}

\subsection{Numerical model}

In order to assess the impact condition the computational model of the viaduct based on design documentation [8] was developed. The numerical model of the impact event consists of 1312278 nodes and 1061836 finite elements. Fig. 3 shows the comparison between the created model and the full-scale WD-113P object.

a)



b)


Fig. 3. The comparison of the computational model and real structure, a) side view, b) bottom view.

To discretize the bridge concrete elements the solid elements have been used with the material model *MAT_CSCM (*MAT_159) [9-12]. This model enable assessing damage of the structure such as cracks or material losses. The T-beams are assigned with the material properties of $\mathrm{C} 35 / 45$ concrete, whereas the crossgirders and bridge slab have properties of $\mathrm{C} 30 / 37$ concrete. The model includes the reinforcement and pre-stressing tendons. The rebars and tendons are represented by beam elements with assumed material model *MAT_PIECEWISE_LINEAR_PLASTICITY (*MAT_024) [10]. The reinforcement is displayed in Fig. 4. The superstructure of the overpass is supported by the columns and abutment. Only the upper column parts and upper circular-shaped parts of the abutment have been modelled. In order to discretize this parts the solid elements with *MAT_RIGID (*MAT_020) [10] material model have been used. 


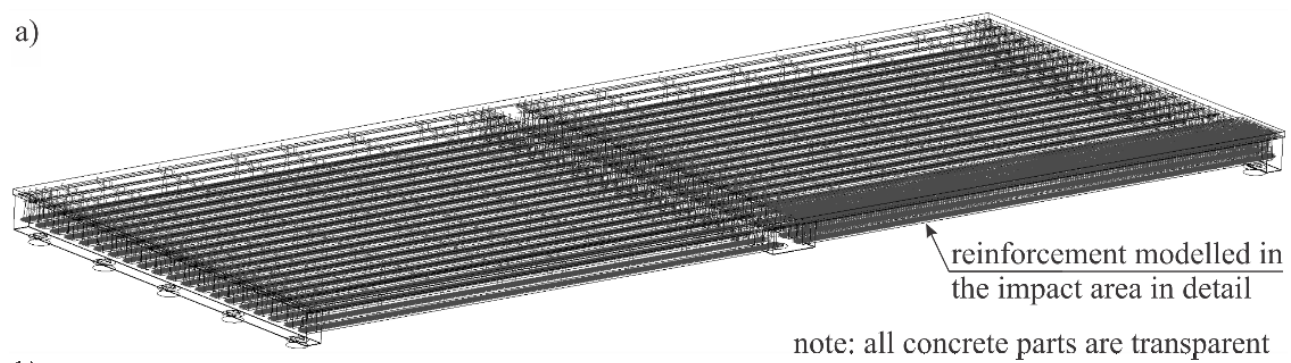

b)

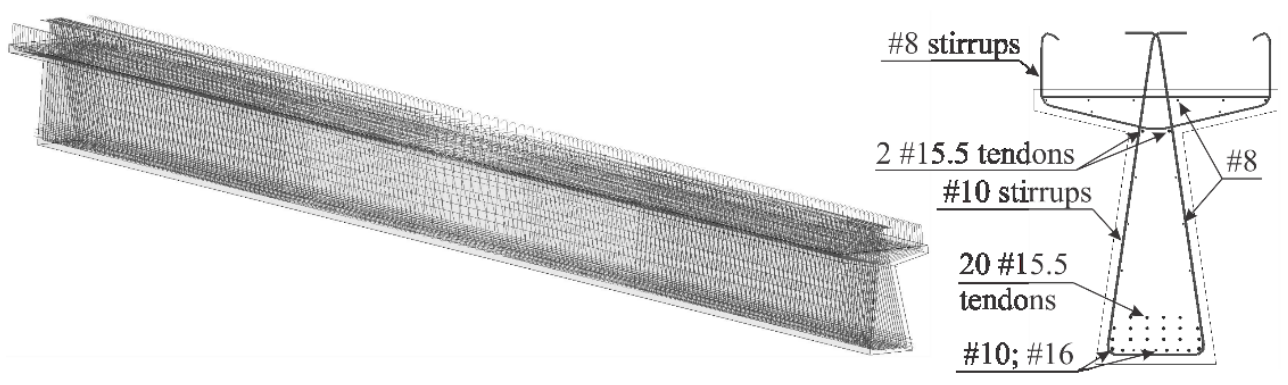

Fig. 4. Reinforcement and tendons included in the computational model, a) the whole reinforcement, b) detail of reinforcement of T-beam.

The friction between all parts of the structure is considered in the computational model. The *CONTACT_AUTOMATIC_GENERAL [13] is used in order to describe contact between rebars and tendons. The contact between concrete parts and between the crossgirders and the supports is modelled by *CONTACT_AUTOMATIC_SINGLE_SURFACE [13].

The connection between steel parts and concrete is provided by the option *CONSTRAINED_LAGRANGE_IN_SOLID [13] which allows creating the finite element mesh of reinforcement independently of concrete discretization.

The performed numerical simulations took into account all construction phases of the bridge structure, i.e. tendon's tensioning (based on [14]) coupling the tendons to the concrete parts and impact of the vehicle.

\subsection{Results of numerical simulation}

Because of the lack of precise data about the mass and velocity of the vehicle at the moment of impact on the viaduct (with the exception of information that the vehicle exceeded the allowed speed $40 \mathrm{~km} / \mathrm{h}$ according to the eye-witnesses), a series of numerical simulations were conducted based on which it was concluded that the speed of the 18.8 ton vehicle striking perpendicular to bridge span should be $50 \mathrm{~km} / \mathrm{h}$.

The damage obtained in the numerical simulations corresponds to damage of the real structure. In particular: losses in concrete in the impact location, long horizontal crack under the flange of the t-beam on both sides, diagonal cracks on both sides of the impact point, hairline crack on the upper surface of the bridge's slab placed between the two end girders. The numerical simulations reveal that the prestressing tendons were not destroyed by the impact. The maximum axial force in the tendons is calculated to be $199.6 \mathrm{kN}$.

Cracking and damage is assumed to be represented by the maximum of brittle and ductile damage form [10]. Fig. 5 shows the comparison of damage of the real structure with the results from numerical simulations. The horizontal and diagonal cracks are marked black in Fig. 5a for the purpose of visibility. 


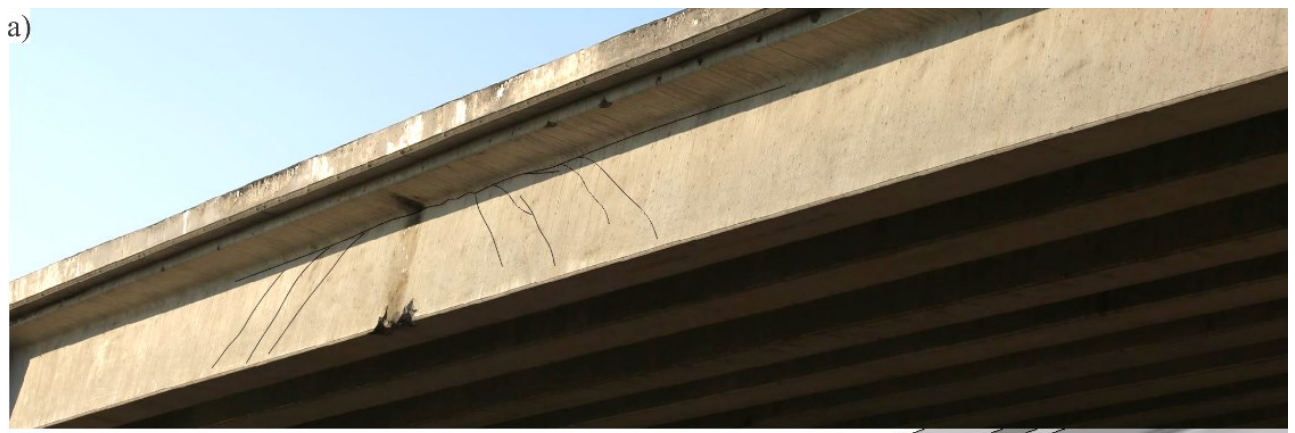

b)

d)

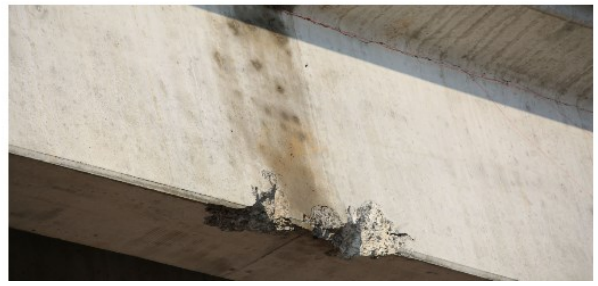

c)

crack on the upper side of the deck loss of concrete between the beams no. 1 and 2 .

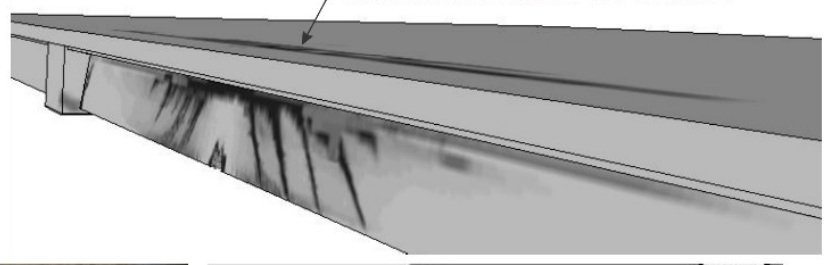

Fig. 5. Damage of concrete, a) reality, b, c) numerical simulation, d) losses in concrete.

\section{Analysis of strengthening of the damaged structure}

The proposed strengthening, according to the documentation [15], is in the form of an additional reinforced concrete beam, which will be placed between two end T-beams. The reinforcement consists of longitudinal reinforcing bars with a diameter of $25 \mathrm{~mm}$ and stirrups. The interaction between the existing bridge structure and the proposed additional beam is implemented by steel anchors. The additional RC beam will be erected after re-profiling and securing the damaged concrete surfaces. 


\subsection{Numerical model}

The structural strengthening was introduced to the computational model of the overpass. The concrete parts are modelled by solid elements. The material *MAT_CSCM (*MAT_159) [10] with properties corresponding to $\mathrm{C} 35 / 45$ concrete is used. The reinforcement is represented by beam elements and material model *MAT_PIECEWISE_LINEAR_PLASTICITY (*MAT_024) [10] is used. The computational model of the strengthened structure consists of 1330386 nodes and 1076027 finite elements. The general view on the strengthening and the detail of its reinforcement can be seen in Fig. 6 and Fig. 7. The impact conditions were assumed the same as for the case discussed in section 3 .

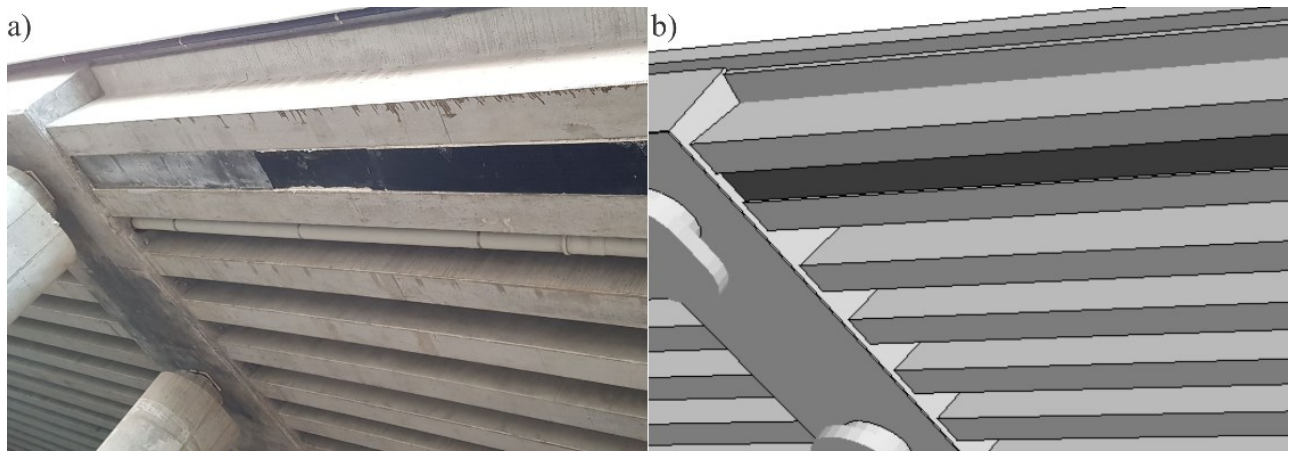

Fig. 6. Comparison between reality (left) and numerical model (right).

a)

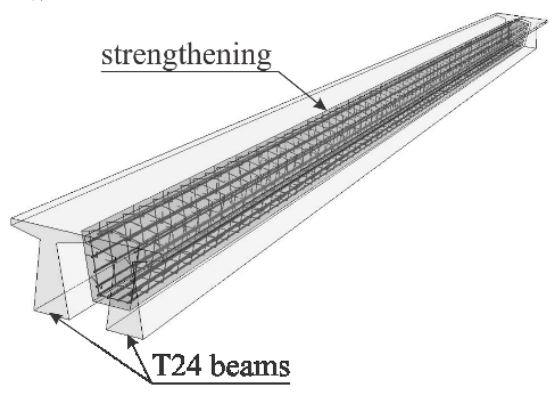

b)



Fig. 7. Detail of strengthening of the overpass, a) general view, b) reinforcement.

\subsection{Effect of the strengthening}

Due to the impact the concrete was damaged and the losses in concrete showed up. The scratches emerged around the impact area as well and an insignificant longitudinal crack appeared under the flange. The longitudinal cracks also showed up on the upper surface of the bridge slab. It should be noted that the aforementioned cracks were much smaller comparing to the situation without the structural strengthening. Moreover, diagonal cracks on both sides of the impact point did not appear. The tendons did not break and the maximum force was $188.3 \mathrm{kN}, 6 \%$ less than in the case of impact into the non-strengthened structure. The additional beam significantly reduced the displacement of reinforcement and prestressing tendons in the most outer T-beam. The influence of strengthening can be clearly visible in Fig. 8 where results of two numerical simulations are compared. 
a)



b)
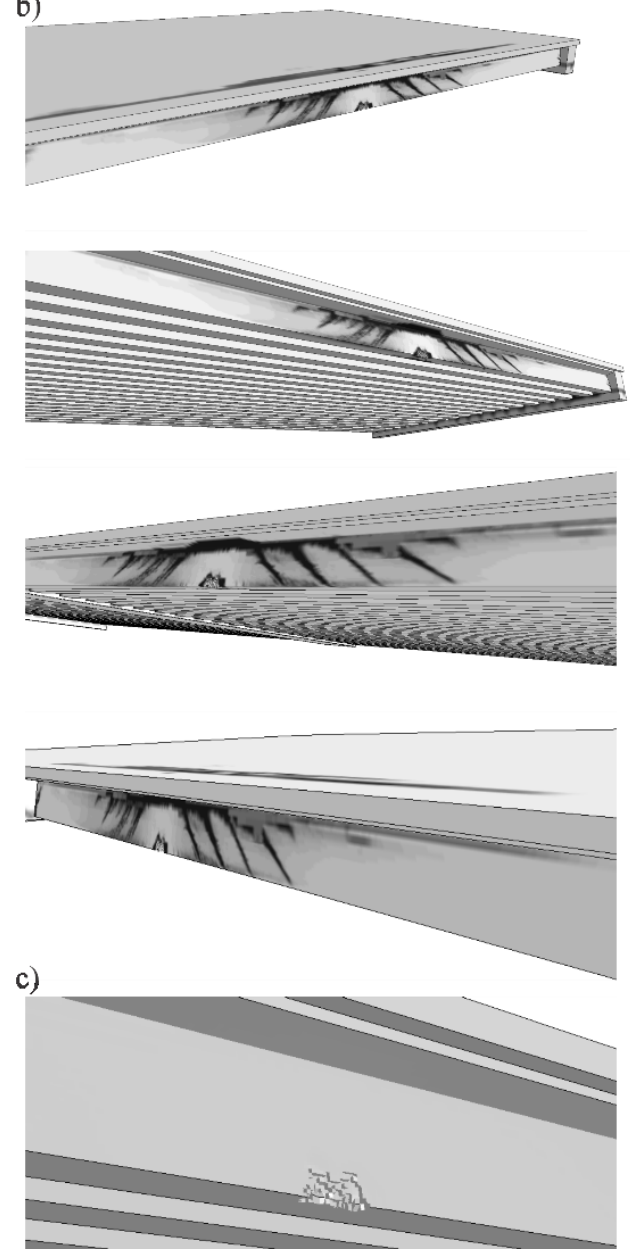
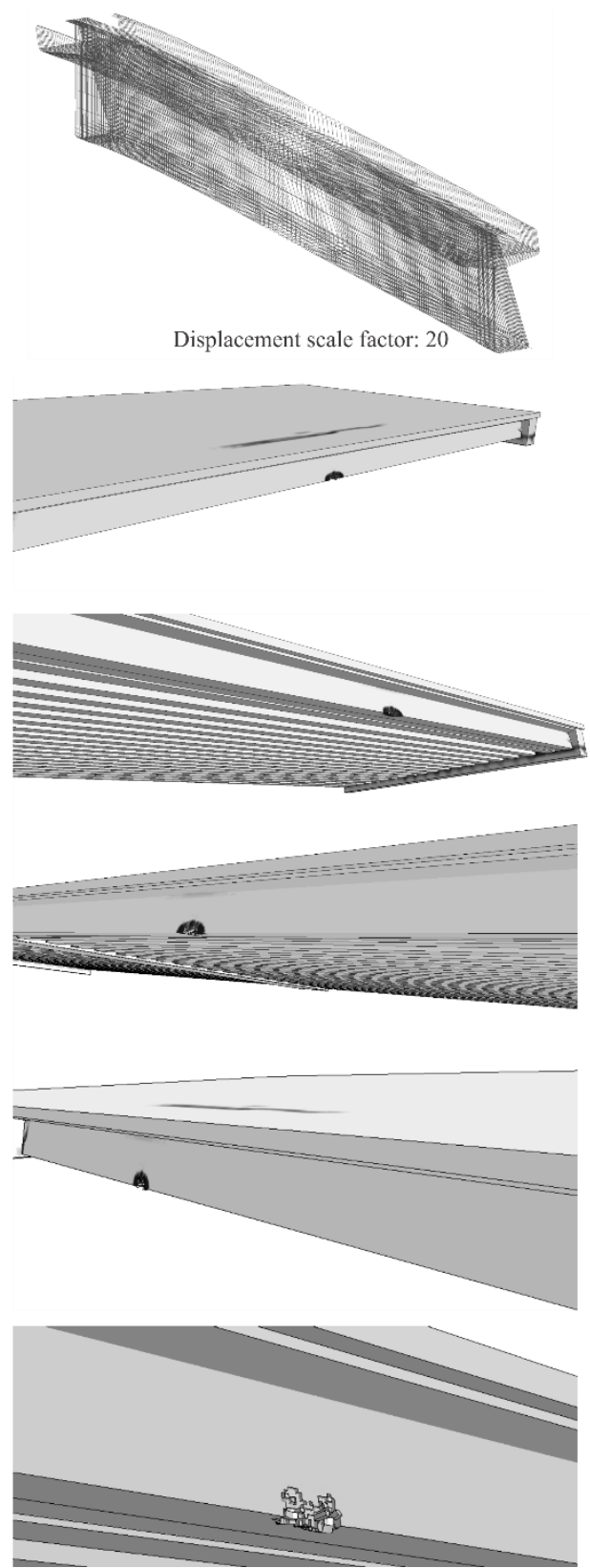

Fig. 8. Comparison of damage of structure with strengthening (right) and without (left), a) displacement of the reinforcement and tendons (note: displacement scale factor is 20), b) cracks, c) losses in concrete.

As a result of constructing the additional beam between the two end girders the stiffness of the structure increases and this allows for significant reduction of potential damage and cracks resulting from the re-impact. Nevertheless, local damage to the concrete and possible scratches under the beam's flange as well as on the upper surface of the bridge slab might arise and shall be repaired. 


\section{Conclusion}

Impacts in viaducts are a common phenomenon. The paper describes the event where in relatively short period of time (less than one month) the span of the overpass under construction was struck twice by the vehicles.

Originally designed structure of the overpass, in which prefabricated T-shaped prestressed concrete beam were used, had no sufficient resistance to transverse forces resulting from vehicle impacts. The implemented repair works increased the strength and safety of the structure and provided additional protection against possible impacts in the future. In order to evaluate the repair concept, with insight into all important data such as plastic deformations of reinforcement or potential damage to the tendons, the advanced numerical simulations have been carried out to assess the condition of the struck viaduct and confirmed the effectiveness of the proposed recovery actions.

Calculations have been carried out at the Academic Computer Centre in Gdańsk (CI TASK), Gdańsk University of Technology, Poland. 


\section{References}

1. D. Zhou, R. Li, J. Wang, C. Guo, Shock Vib., 2017 (2017)

2. M. Yang, P. Qiao, Int. J. Impact Eng., 37(12), pp. 1220-1228 (2010)

3. K. Wilde, D. Bruski, S. Burzyński, J. Chróścielewski, W. Witkowski, Numerical crash analysis of the cable barrier [in:] Mathematical and numerical aspects of dynamical system analysis, 2, pp. 555-566 (2017) [in Polish]

4. A. Agrawal, X. Xu, Finite Element Simulation of Truck Impacts on Highway Bridge Piers (The City College of New York, New York, 2016)

5. J. Chróścielewski, M. Miśkiewicz, Ł. Pyrzowski, B. Sobczyk, Arch. Civ. Eng. 63(3), pp. 3-18 (2017) [in Polish]

6. M. Kulpa, T. Siwowski, Failure analysis and repair assessment of a steel box girder bridge, IOP Conf. Ser. Mater. Sci. Eng., 419(1), 012003 (2018)

7. K. Wilde, K. Jamroz, D. Bruski, M. Budzyński, S. Burzyński, J. Chróścielewski, W. Witkowski, AoCE, 63(2), pp. 187-199 (2017) [in Polish]

8. Design project: Wiadukt WD-113 w ciagu drogi S-6 $w \mathrm{~km} 2+842,39$ opracowany na potrzeby przedsięwzięcia Budowa obwodnicy Koszalina $i$ Sianowa na S-6 wraz z odcinkiem S-11 od węzła „Koszalin” do węzła „Bielice” (MP-MOSTY Sp. z o.o., 2015) [in Polish]

9. J.O. Halquist, LS-DYNA Theory Manual (Livermore Software Technology Corporation, Livermore, USA, 2006)

10. LS-DYNA, Keyword User's Manual. Vol. II. Material Models (Livermore Software Technology Corporation, Livermore, USA, 2015)

11. Y. D. Murray, FHA, User's Manual for LS-DYNA Concrete Material Model 159, (Federal Highway Administration, Georgetown Pike, USA, 2007)

12. Y.D. Murray, A. Abu-Odeh, R. Bligh, FHA, Evaluation of LS-DYNA Concrete Material Model 159, (Federal Highway Administration, Georgetown Pike, USA, 2007)

13. LS-DYNA, Keyword User's Manual. Vol. I. (Livermore Software Technology Corporation, Livermore, USA, 2015)

14. L.E. Schwer, Modeling Pre and Post Tensioned Concrete (Proceedings of $14^{\text {th }}$ Int. LS-DYNA Users Conf., Detroit, USA, 2016)

15. Design project: Wzmocnienie uszkodzonej belki $T$ wiaduktu WD-113 (PORR S.A./MOSTY GDAŃSK Sp. z o.o., 2018) [in Polish] 